\section{OPEN ACCESS}

Edited by: Leonard Peruski,

US Centers for Disease Control and Prevention, USA

Reviewed by:

Haider Abdul-Lateef Mousa,

University of Basrah, Iraq

Haiyong Guo,

Jilin Normal University, China

*Correspondence:

Chaoman Situ

situcm@hotmail.com

Qinghua Hu

huqinghua03@163.com

Specialty section: This article was submitted to

Infectious Diseases,

a section of the journa

Frontiers in Microbiology

Received: 01 July 2016 Accepted: 16 November 2016 Published: 30 November 2016

Citation:

Shen $H$, Zhang J, Li Y, Xie S, Jiang $Y, W u Y, Y e Y$, Yang $H$, Mo $H$,

Situ C and Hu Q (2016) The 12 Gastrointestinal Pathogens Spectrum of Acute Infectious Diarrhea in a Sentinel Hospital, Shenzhen, China.

Front. Microbiol. 7:1926.

doi: 10.3389/fmicb.2016.01926

\title{
The 12 Gastrointestinal Pathogens Spectrum of Acute Infectious Diarrhea in a Sentinel Hospital, Shenzhen, China
}

\begin{abstract}
Hongwei Shen ${ }^{1}$, Jinjin Zhang ${ }^{1}$, Yinghui $L^{2}{ }^{2}$, Sirou Xie ${ }^{1}$, Yixiang Jiang ${ }^{2}$, Yanjie $W u^{3}$, Yuhui $\mathrm{Ye}^{3}$, Hong Yang ${ }^{3}$, Haolian Mo ${ }^{1}$, Chaoman Situ ${ }^{1 *}$ and Qinghua $\mathrm{Hu}^{2 *}$
\end{abstract}

\begin{abstract}
${ }^{1}$ Futian District Center for Disease Control and Prevention, Shenzhen, China, ${ }^{2}$ Shenzhen Major Infectious Disease Control Key Laboratory, Shenzhen Center for Disease Control and Prevention, Shenzhen, China, ${ }^{3}$ Peking University Shenzhen Hospital, Shenzhen, China
\end{abstract}

Acute infectious gastroenteritis is one of the most common diseases among all ages, particularly in developing countries. The pathogen spectrum may differ among different regions and seasons. To investigate the etiology of acute diarrhea in Shenzhen, a prospective study was conducted from August 2014 to September 2015. Stools from 412 patients with diarrhea (286 of whom were adults) including the general epidemiological information of the patients were collected. The 19 pathogens were detected by conventional culture method or multiplex PCR assay, which included five viruses (rotavirus, adenovirus, sapovirus, norovirus, and astrovirus), 11 bacterial pathogens (Salmonella, Campylobacter jejuni, Shigella, Listeria monocytogenes, Vibrio parahaemolyticus, Vibrio cholera, Enterohemorrhagic (EHEC), enteropathogenic (EPEC), enteroinvasive (EIEC), enterotoxigenic (ETEC); and enteroaggregative Escherichia coli (EAEC)) and three parasites (Entamoeba histolytica, Giardia lamblia, and Cryptosporidium parvum). A potential pathogen and coinfection was found in 41.5 and $7.0 \%$ of cases, respectively. The bacterial infection was the dominant cause of diarrhea (32.3\%), and the three most frequently identified organisms were Salmonella (12.1\%), ETEC (8.0\%), and Campylobacter jejuni (4.9\%). Salmonella enteritidis was the leading serotype of Salmonella sp. Norovirus (8.3\%) and sapovirus (2.2\%) were the most common viral pathogens, followed by adenovirus (1.5\%) and rotavirus (1.2\%). No EHEC, L. monocytogenes, $V$. cholera, Shigella, and parasites were found. The single most important causes of diarrhea were Salmonella spp. and Campylobacter jejuni, which points toward the need for testing and surveillance for these pathogens in this region.

Keywords: gastrointestinal pathogen, spectrum, acute infectious diarrhea, sentinel hospital, Shenzhen

\section{INTRODUCTION}

Acute infectious diarrhea accounts for substantial morbidity and mortality in all regions in the world and among all ages (Fischer Walker et al., 2010), with over 2 million death occurring each year, particularly among infants younger than 5 years (Clarke et al., 2003; Kosek et al., 2003). In developing countries, such as China, the associated mortality is high because of the high incidence and poor medical condition in some regions. A broad range of organisms have been recognized as the etiologies of acute infectious diarrhea. Rotavirus is known as the most common cause of severe acute gastroenteritis among children (Parashar et al., 2003). Norovirus infection is responsible for 
most outbreaks of nonbacterial gastroenteritis (Yan et al., 2003). Shigella sp., V. parahaemolyticus, Salmonella sp., and diarrheagenic Escherichiacoli (DEC) are frequently detected agents associated with acute infectious diarrhea (Huilan et al., 1991; Bai et al., 2004; Qu et al., 2012). C. jejuni is one of the most common causes of gastroenteritis worldwide and its prevalence is particularly high in developed countries (Allos, 2001; Koopmans et al., 2001; Scallan et al., 2011). Furthermore, some less common pathogens, such as astrovirus, and parasites may also cause acute diarrhea (Olesen et al., 2005; Denno et al., 2012).

Although these common enteropathogens have been extensively studied in China (Bai et al., 2004; Qu et al., 2012; Li et al., 2014), and the laboratory-based surveillance for acute infectious diarrhea has been established in Shenzhen City since 2007, few comprehensive studies covering a broad range of diarrheal agents have been undertaken. Furthermore, the long-term fluctuation in the frequency of infections with the common gastrointestinal pathogens captured by this surveillance system suggested the etiology of acute infectious diarrhea in this region has changed obviously during the past few years. To investigate the etiology of diarrhea, thus informing policy makers on future vaccine and intervention development in the southern coastal region of China, the present study, comprising testing for bacteria, virus, and parasites, was conducted.

\section{MATERIALS AND METHODS}

\section{Specimen Collection}

Acute diarrhea was defined as $\geq 3$ passages of watery, loose, mucus-, or bloody-stools during a 24 -h period. Stool samples were consecutively collected by Peking University Shenzhen Hospital from patients who presented with acute diarrhea to the diarrhea outpatient clinics during the period from August 2014 through September 2015. A total of 412 patients without receiving antibiotics treatment could provide a stool specimen during the visit, aged from 1 month to 78 years old, were enrolled in this study. A brief questionnaire including demographic data and clinical signs was filled out from patients or their guardians. The feces were stored at $4^{\circ} \mathrm{C}$ and transported to the laboratory of Futian District Center for Disease Control and Prevention (Futian CDC) in two days during workdays or 3 days during weekends.

\section{Sample Processing}

The stool samples were enriched in selective broth medium or cultured on different medium immediately to obtain bacterial strains. If the stool sample volumes were insufficient, the stools were diluted using PBS before bacterial culture. The remaining specimens were prepared as $20 \%$ stool suspension in PBS and kept at $-60^{\circ} \mathrm{C}$ until further study. The viral and bacterial nucleic acid was extracted and purified using the High Pure Viral Nucleic Acid Kit (Roche Diagnostics, Mannheim, Germany) and QIAamp Fast DNA Stool Mini Kit (Qiagen GmbH, Hilden, Germany), respectively, according to the manufacturer's recommended protocols. The stool suspension was heated for $10 \mathrm{~min}$ at $100^{\circ} \mathrm{C}$ and then DNA of parasites was isolated with
QIAamp DNA Mini Kit (Qiagen GmbH, Hilden, Germany). Purified nucleic acid was frozen at $-80^{\circ} \mathrm{C}$ in $15-\mu l$ aliquots.

\section{Bacteria Isolation}

The CHROM agars were used for isolation of Salmonella sp., Vibrio parahaemolyticus, and Vibrio cholera; HE medium and Campylobacter-selective agar for Shigella sp. and C. jejuni, respectively. Specimens were enriched in selenite cysteine (SC) broth and $3 \% \mathrm{NaCl}$ peptone water before plated on CHROM agar for isolation of Salmonella sp. and Vibrio sp., respectively. The Salmonella isolates from CHROM agar were identified using the Sensititre GNID (TREK Diagnostic System, Cleveland, OH, USA) and serotyped with a commercial serotyping kit (S\&A Company, S\&A Reagent Lab, Bangkok, Thailand) according to the manufacturer's instructions. All the V. parahaemolyticus isolates were identified using the Sensititre GNID (TREK Diagnostic System, Cleveland, OH, USA) and serotyped with a commercial serotyping kit (Denka Seiken, Tokyo, Japan), followed by real-time PCR detection of the thermostable direct hemolysin $(t d h)$ and thermolabile hemolysin $(t r h)$ genes (Blackstone et al., 2003; Davis et al., 2004). Stool samples were examined for diarrhoeagenic $E$. coli by detecting virulence loci of a pool of three suspicious clonies from MacConkey Agar Plate, such as eaeA, stx $x_{1}$, and $s t x_{2}$ of enterohemorrhagic E. coli (EHEC); eaeA and escV of enteropathogenic E. coli (EPEC); ipaH of enteroinvasive E. coli (EIEC) and Shigella strains; lt, sth, and stp of enterotoxigenic E. coli (ETEC); and $a g g R$ of enteroaggregative E. coli (EAEC) (Chen et al., 2014). To reduce the risk of false negative results, the multiple PCR method simultaneously detecting five bacterial pathogens associated with diarrhea and the PCR assay targeting DEC were adopted to screening the purified nucleic acid (Chen et al., 2014; Hu et al., 2014).

The oligonucleotide primers and probes used for real-time PCR for simultaneous detection of virulence loci of DEC and simultaneous detection of five enteric bacteria were listed in Table 1. A common tag sequence was added at the $5^{\prime}$ end of each primer to minimum the formation of primer dimer. The amplification reaction was the same as previously described (Chen et al., 2014; Hu et al., 2014). The cycling conditions included a initiating stage of $3 \mathrm{~min}$ at $95^{\circ} \mathrm{C}$ followed by 5 cycles of $10 \mathrm{~s}$ at $95^{\circ} \mathrm{C}, 20 \mathrm{~s}$ at $58^{\circ} \mathrm{C}$, and $15 \mathrm{~s}$ at $72^{\circ} \mathrm{C}$ and finally by a 40 cycles of $10 \mathrm{~s}$ at $94^{\circ} \mathrm{C}, 20 \mathrm{~s}$ at $55^{\circ} \mathrm{C}$, and $15 \mathrm{~s}$ at $72^{\circ} \mathrm{C}$ (Bio-Rad CFX96, Bio-Rad, USA).

\section{Virus Detection}

Reverse transcription-PCR (RT-PCR) was performed by using PrimerScript First strand cDNA Synthesis Kit (TaKaRa, China). Viral RNA was reverse transcribed for $10 \mathrm{~min}$ at $30^{\circ} \mathrm{C}, 50 \mathrm{~min}$ at $42^{\circ} \mathrm{C}$, and $5 \mathrm{~min}$ at $95^{\circ} \mathrm{C}$. A single real-time multiplex PCR assay was followed for simultaneous detection of five enteric viruses: norovirus genogroups I and II; sapovirus genogroups I, II, IV, and V; human rotavirus A; adenovirus serotypes 40 and 41; and human astrovirus (Jiang et al., 2014). The specific primers and probes used in this reaction were presented in Table 1. Each primer had a common tag sequence at the $5^{\prime}$ end of the sequence. A combination of two probes for Norovirus GI was designed in order to differentiate the five organisms under four 
TABLE 1 | The oligonucleotide primers and probes for real-time PCR used in this study.

\begin{tabular}{|c|c|c|c|c|}
\hline Organism & Target gene $\mathrm{a}^{\mathrm{a}}$ & Primer sequence $\left(5^{\prime}-3^{\prime}\right)^{b}$ & Probe $\left(5^{\prime}-3^{\prime}\right)$ & Citation \\
\hline Tag & / & GCAAGCCCTCACGTAGCGAA & / & Chen et al., 2014 \\
\hline \multicolumn{5}{|l|}{ DEC } \\
\hline ETEC ${ }^{1}$ & stp & $\begin{array}{l}\text { F: AAAAGCGAGTGTACCTCGACA } \\
\text { R: CAGTTGACTGACTAAAAGAGGGG }\end{array}$ & $\begin{array}{l}\text { HEX-CGCGTCTCAAATATCCGTGA } \\
\text { AACAACATGACGCG }\end{array}$ & Chen et al., 2014 \\
\hline ETEC $^{1}$ & sth & $\begin{array}{l}\text { F: GTGGTCCTGAAAGCATGAATAG } \\
\text { R: CAACAAAGCAACAGGTACATACG }\end{array}$ & $\begin{array}{l}\text { FAM-CGCGGTGAATTGTGTTGTAATCCTGCTTG } \\
\text { TACCGCG }\end{array}$ & Chen et al., 2014 \\
\hline ETEC $^{1}$ & It & $\begin{array}{l}\text { F: ACAGGAGGTTTCTGCGTTAG } \\
\text { R: GGTGGGAAACCTGCTAATCT }\end{array}$ & $\begin{array}{l}\text { ROX-CGCCGGTATTACAGAAATCTGAA } \\
\text { TATAGCTCCGGCG }\end{array}$ & Chen et al., 2014 \\
\hline EAEC $^{1}$ & aggR & $\begin{array}{l}\text { F: TGCAAAAGAAGAAATCAACAGT } \\
\text { R: CAGAATCGTCAGCATCAGCTAC }\end{array}$ & CY5-CGGACAAAAGTAGATGCTTGCAGTTGTCCG & Chen et al., 2014 \\
\hline $\mathrm{EIEC}^{2}$ & ipaH & $\begin{array}{l}\text { F: GAAAACCCTCCTGGTCCATC } \\
\text { R: GTCTGGAAGGCCAGGTAGACTT }\end{array}$ & FAM-CCCGGCTGGAGGACATTGCCCGGG & Chen et al., 2014 \\
\hline EPEC\&EHEC ${ }^{2}$ & eaeA & $\begin{array}{l}\text { F: GTAACCAGGCTTCGTCACA } \\
\text { R: AAGGAAAAAACGCTGACCCG }\end{array}$ & $\begin{array}{l}\text { CY5-CCCAGTGGTAATAACTTTGACGGTAG } \\
\text { TTCACTGGG }\end{array}$ & Chen et al., 2014 \\
\hline EPEC\&EHEC ${ }^{2}$ & escV & $\begin{array}{l}\text { F: GGCTCTCTTCTTCTTTATGGCTG } \\
\text { R: GGGAAAGAAGTAGTTCAAGAGGAT }\end{array}$ & $\begin{array}{l}\text { HEX-CCCGCGCAACAGTTGTGGTGGATATCATTAT } \\
\text { CGCGGG }\end{array}$ & Chen et al., 2014 \\
\hline EHEC $^{2}$ & stx 1 & $\begin{array}{l}\text { F: ASAGCGGTTACATTGTCTGGT } \\
\text { R: CTGCGTCAGTGAGGTTCCA }\end{array}$ & $\begin{array}{l}\text { ROX- CCGCGTACGGGGATGCAGA } \\
\text { TAAATCGCGG }\end{array}$ & Chen et al., 2014 \\
\hline EHEC $^{2}$ & $s t \times 2$ & $\begin{array}{l}\text { F: CATGACAACGGACAGCAGTTA } \\
\text { R: TCTGGTCATTGTATTACCACTGAA }\end{array}$ & ROX-CCGCCACTCACTGGTTTCATCATATCTGGCGG & Chen et al., 2014 \\
\hline \multicolumn{5}{|l|}{ Bacteria } \\
\hline L. monocytogenes ${ }^{3}$ & hly & $\begin{array}{l}\text { F: TGCAAGTCCTAAGACGCCA } \\
\text { R: CACTGCATCTCCGTGGTATACTAA }\end{array}$ & $\begin{array}{l}\text { ROX-CGCGCTTGTATATACTTATCGATTTC } \\
\text { ATCCGCGCG }\end{array}$ & Hu et al., 2014 \\
\hline V. parahaemolyticus ${ }^{3}$ & toxR & $\begin{array}{l}\text { F: AAGCGCCAGTAGTACCTGA } \\
\text { R: CCAATCTGACGGAACTGAGATT }\end{array}$ & FAM/HEX-CGGCAAATCGGTAGTAATAGTGCCG & Hu et al., 2014 \\
\hline Salmonella ${ }^{3}$ & $S P I$ & $\begin{array}{l}\text { F: GAACCTGGCCTGAAGACATAAA } \\
\text { R: AGGTCAATAGCCAGAAAGGGA }\end{array}$ & CY5-CCGGCTAACTGACTCACCGTAAATGCCGG & Hu et al., 2014 \\
\hline C. jejuni3 & gyrA & $\begin{array}{l}\text { F: AGTGCG(C/A)GCTAAAACTCA } \\
\text { R: CAAGCTCTGCAATCTGCTC }\end{array}$ & FAM-CCGCCTTATCAAACCAATAAAGCTAGGCGG & Hu et al., 2014 \\
\hline Shigella ${ }^{3}$ & ipaH & $\begin{array}{l}\text { F: TGAAGGAAATGCGTTICTATG } \\
\text { R: AGGGAGAACCAGTCCGTAAA }\end{array}$ & $\begin{array}{l}\text { HEX-CACGGCCGAAGCTATGGTC } \\
\text { AGAAGCCGTG }\end{array}$ & Hu et al., 2014 \\
\hline \multicolumn{5}{|l|}{ Virus } \\
\hline Sapovirus ${ }^{4}$ & RdRp & $\begin{array}{l}\text { F: CTCGCCACCTACAATGCYTGGTT } \\
\text { R: TGGGATGTGGTCGGVCCAGT }\end{array}$ & $\begin{array}{l}\text { FAM-CCGAGCCTAGTGTTTGAGATGGAGGGCAAT } \\
\text { GGCTCGG }\end{array}$ & Jiang et al., 2014 \\
\hline Sapovirus ${ }^{4}$ & VP1 & $\begin{array}{l}\text { F: ACRGCCAARGCTGAGGGG } \\
\text { R: CCCTCCATTCAAACACTAATT }\end{array}$ & FAM-CCCTGGGCCCCAGTGAAGAGACCACCAGGG & Jiang et al., 2014 \\
\hline Norovirus $\mathrm{Gl}{ }^{4}$ & VP1 & $\begin{array}{l}\text { F: CGCTGGATGCGNTTCCAT } \\
\text { R: CCTTAGACGCCATCATCATTTAC }\end{array}$ & $\begin{array}{l}\text { FAM/HEX-CCGTGGAAGATYGCG } \\
\text { RTCTCCTGTCCACGG }\end{array}$ & Jiang et al., 2014 \\
\hline Norovirus GII ${ }^{4}$ & VP1 & $\begin{array}{l}\text { F: ATGTTCAGRTGGATGAGRTTCTCWGA } \\
\text { R: TCGACGCCATCTTCATTCACA }\end{array}$ & ROX-CGCACGATCGCCCTCCCACGTGCG & Jiang et al., 2014 \\
\hline Adenovirus $^{4}$ & hexon & $\begin{array}{l}\text { F: TACTTCAGCCTGGGGAACAAG } \\
\text { R: CAGCGTAAAGCGCACTTG }\end{array}$ & $\begin{array}{l}\text { CY5-CCCACGCCTGTCTGTGGTT } \\
\text { ACATCGTGGG }\end{array}$ & Jiang et al., 2014 \\
\hline Rotavirus ${ }^{4}$ & NSP3 & $\begin{array}{l}\text { F: ACCATCTACACATGACCCTC } \\
\text { R: CACATAACGCCCCTATAGCC }\end{array}$ & $\begin{array}{l}\text { HEX-CCGAGCACAATAGTTAAAA } \\
\text { GCTAACACTGTCGCTCGG }\end{array}$ & Jiang et al., 2014 \\
\hline Astrovirus ${ }^{4}$ & ORF1 & $\begin{array}{l}\text { F: ATCCGTGATGTTAATGGG } \\
\text { R: CGTTGCCAGAAAAGAAGC }\end{array}$ & $\begin{array}{l}\text { FAM/CY5-CGCGACACCCCTGAA } \\
\text { GGGAAAGGGACAGTCGCG }\end{array}$ & Jiang et al., 2014 \\
\hline \multicolumn{5}{|l|}{ Parasites } \\
\hline E. histolytica ${ }^{5}$ & SSU rRNA & $\begin{array}{l}\text { F: ATTGTCGTGGCATCCTAACTCA } \\
\text { R: GCGGACGGCTCATTATAACA }\end{array}$ & VIC-TCATTGAATGAATTGGCCATTT & Verweij et al., 2004 \\
\hline G. lamblia ${ }^{5}$ & SSU rRNA & $\begin{array}{l}\text { F: GACGGCTCAGGACAACGGTT } \\
\text { R: TTGCCAGCGGTGTCCG }\end{array}$ & FAM-CCCGCGGCGGTCCCTGCTAG & Verweij et al., 2004 \\
\hline C. parvum ${ }^{5}$ & DNAj-like & $\begin{array}{l}\text { F: CGCTTCTCTAGCCTTTCATGA } \\
\text { R: CTTCACGTGTGTTTGCCAAT }\end{array}$ & $\begin{array}{l}\text { Texas Red-CCAATCACAGAATCA } \\
\text { TCAGAATCGACTGGTATC }\end{array}$ & Verweij et al., 2004 \\
\hline
\end{tabular}

${ }^{a}$ stp, sth, heat-stable enterotoxin; It, heat-labile enterotoxin; aggR, transcriptional regulator aggR; ipaH, invasive plasmid antigen $\mathrm{H}$; eaeA, intimin; escV, enterocyte effacement gene locus; stx1, shiga toxin 1; stx2, shiga toxin 2; hly, listeriolysin O; toxR, transmembrane regulatory protein; SPI, specific pathogenicity island; gyrA, DNA gyrase subunit A; RdRp, RNA-dependant RNA Polymelase; VP1, capsid protein VP1; NSP3, nonstructural protein 3; ORF1, nonstructural protein; SSU rRNA, small subunit ribosomal RNA. ${ }^{\mathrm{b}}$, forward; $R$, reverse. ${ }^{1}$ tube $1 ;{ }^{2}$ tube $2 ;{ }^{3}$ tube $3 ;{ }^{4}$ tube $4 ;{ }^{5}$ tube 5. 
detecting channels. The amplification reaction was consistent with previously described and cycling condition was the same as that of simultaneous detecting virulence loci of DEC or five enteric bacteria (Jiang et al., 2014).

\section{Parasites Detection}

A multiplex PCR method with high sensitivity and specificity was adopted to simultaneous detection of the three most common diarrhea-causing parasitic protozoa, including Entamoeba histolytica, Giardia lamblia, and Cryptosporidium parvum (Verweij et al., 2004).

All primers and detection probes used for real-time PCR for simultaneous detection of the three parasites were described in Table 1. Amplification reactions were carried out as previously described (Verweij et al., 2004), which consisted of $15 \mathrm{~min}$ at $95^{\circ} \mathrm{C}$ followed by 40 cycles of $15 \mathrm{~s}$ at $95^{\circ} \mathrm{C}, 30 \mathrm{~s}$ at $60^{\circ} \mathrm{C}$, and $30 \mathrm{~s}$ at $72^{\circ} \mathrm{C}$. Amplification, detection and data analysis were performed in a Bio-Rad CFX96 real-time thermal cycler (Bio-Rad, USA).

\section{Ethics Statement}

All aspects of the study were performed in accordance with national ethics regulations and approved by the Ethics Committee of Peking University Shenzhen Hospital, as well as Futian District CDC. Participants received information on the study's purpose and of their right to keep information confidential. Written consent was obtained from each adult participant and children's parents or their guardians.

\section{RESULTS}

\section{Epidemiological Information}

A total of 412 cases (184 of whom were part of the transient population) were enrolled in the prospective study in the12month period. Patients ranged in age from 1 month to 78 years

TABLE 2 | The epidemiological and clinical characteristics of samples $(n=412)$ in this study.

\begin{tabular}{lcc}
\hline Category & Subcategory & No. (\%) \\
\hline Sex & Female & $231(56.1)$ \\
Age (years) & Male & $181(43.9)$ \\
& $0 \sim 4$ & $107(26.0)$ \\
& $5 \sim 9$ & $5(1.2)$ \\
Residence & $10 \sim 19$ & $25(6.1)$ \\
& $20 \sim 29$ & $71(17.2)$ \\
Clinical Manifestations & $30 \sim 39$ & $71(17.2)$ \\
& $40 \sim 49$ & $61(14.8)$ \\
& $50 \sim 59$ & $42(10.2)$ \\
& 60 and above & $30(7.3)$ \\
& Transient population & $228(55.3)$ \\
& Local population & $184(44.7)$ \\
& Abdominal pain & $211(51.2)$ \\
& Vomiting & $68(16.5)$ \\
& Flood in stools & $28(6.8)$ \\
& & $14(3.4)$
\end{tabular}

(median 28 years). Of all the patients, 211 (51.2\%) had abdominal pain, 68 (16.5\%) had vomiting, 28 (6.8\%) had fever, and $14(3.4 \%)$ had blood in stools, respectively (Table 2). Stools from 297 of all cases contain enough material for thorough microbiologic evaluation without dilution. Overall, a potential pathogen was found in $41.5 \%$ of all cases who had loose or liquid stools.

\section{Gastrointestinal Pathogens Spectrum}

Among all samples tested, a bacterial pathogen was found in 107 (26.0\%) of cases (Salmonella sp., 37 specimens; ETEC, 20; C. jejuni, 18; EPEC, 16; EAEC, 8; V. parahaemolyticus, 4; and EIEC, 4); a virus was found in $35(8.5 \%)$ of cases (norovirus GII, 24 specimens; adenovirus, 4; sapovirus, 3; rotavirus, 3; and astrovirus, 1); both viral and bacterial infection was found in 15 (3.6\%) of cases (EAEC and sapovirus, 2 specimens; ETEC and sapovirus, 2; ETEC and norovirus GII, 2; C. jejuni, and norovirus GII 2; EPEC and norovirus GII, 1; EPEC and adenovius, 1; Salmonella sp. and norovirus GII, 1; Salmonella sp. and sapovirus, 1; Salmonella sp., EPEC and norovirus GII, 1; Salmonella sp., ETEC and rotavirus, 1; Salmonella sp., and adenovirus and sapovirus, 1). Mixed bacterial infection was found in $11(2.7 \%)$ of cases (Salmonella sp. and ETEC, 5 specimens; EPEC and ETEC, 2; Salmonella sp. and EPEC, 1; Salmonella sp. and EAEC, 1; EPEC and EAEC, 1; Salmonella sp., EPEC and ETEC, 1). Sample from one patient yielded norovirus GII and rotavirus; and from two patients yielded both norovirus GII and astrovirus. No EHEC, L. monocytogenes, Shigella, V. cholera, and parasites were isolated or found (Table 3 ).

The seasonal prevalence was most prominent for Salmonella, V. parahaemolyticus, ETEC, EAEC, and EPEC, with most infections seen in summer season (April through October), including 49 of 50 Salmonella infection, 4 of 4 $V$. parahaemolyticus, 32 of 33 ETEC, 11 of 12 EAEC, and 23 of 24 EPEC were found during this period. The infection with norovirus tended to occur throughout the year. The viral infection was commonly found in children aged under 5 years. Salmonella was seemly found in all age groups with high prevalence (Table 4).

\section{Serotyping and Genotyping}

One of the most frequently isolated bacterial pathogen was Salmonella sp. Several serotypes were identified: serovars Enteritidis, Senftenberg, Typhimurium, Litchfield, Stanley, London, Derby, Essen, Chomedy, Fillmore, Manchester, Papuana, Uganda, and untypable in 12 , 5, 4, 4, 4, 2, 1, 1, 1, 1, 1, 1, 1 , and 2 patients, respectively (Table 5). C. jejuni was identified from 20 cases, and was the third most common bacterial cause of diarrhea. All the three $V$. parahaemolyticus isolates of serotype O3:K6 were $t d h+t r h-$. The suspected colonies from 47 samples were DEC positive, including 1 EIEC, 8 EAEC, 16 EPEC, and 22 ETEC identified by multiplex PCR assay, whereas additional 3 EIEC, 3 EAEC, 7 EPEC, and 9 ETEC were identified in purified nucleic acids from stool samples. Twenty of twenty-two EPEC infections were eaeA positive. Of the 33 ETEC infections, 14 were $l t$ positive, 14 were sth positive, 4 were stp positive, and one were $s t h+l t$ positive. The isolation results of $V$. cholera and Shigella were in consistent with PCR method. Additional 10 
TABLE 3 | Pathogens detected in 412 tool samples isolated from the acute diarrhea patients by culture/ multiplex PCR method.

\begin{tabular}{|c|c|c|}
\hline Organism & No. of patients & Co-infection \\
\hline C. jejuni & 20 & 2 with norovirus Gll \\
\hline EAEC & 12 & $\begin{array}{l}2 \text { with sapovirus, } 1 \text { with Salmonella, } \\
\text { and } 1 \text { with EPEC }\end{array}$ \\
\hline EIEC & 4 & \\
\hline EPEC & 24 & $\begin{array}{l}2 \text { with ETEC, } 1 \text { with Salmonella, } 1 \text { with } \\
\text { adenovirus, } 1 \text { with norovirus Gll, } 1 \text { with } \\
\text { Salmonella and ETEC, and } 1 \text { with } \\
\text { Salmonella and norovirus Gll }\end{array}$ \\
\hline ETEC & 33 & $\begin{array}{l}5 \text { with Salmonella, } 2 \text { with sapovirus, } 2 \\
\text { with norovirus Gll, and } 1 \text { with } \\
\text { Salmonella and rotavirus }\end{array}$ \\
\hline Salmonella sp. & 50 & $\begin{array}{l}1 \text { with sapovirus, } 1 \text { with norovirus Gll, } \\
\text { and } 1 \text { with sapovirus and adenovirus }\end{array}$ \\
\hline V. parahaemolyticus & 4 & \\
\hline Adenovirus & 6 & \\
\hline Norovirus & 34 & 2 with astrovirus, 1 with rotavirus \\
\hline Rotavirus & 5 & \\
\hline Sapovirus & 9 & \\
\hline Astrovirus & 3 & \\
\hline EHEC & 0 & \\
\hline L. monocytogenes & 0 & \\
\hline Shigella & 0 & \\
\hline V. cholera & 0 & \\
\hline E. histolytica & 0 & \\
\hline G. lamblia & 0 & \\
\hline C. parvum & 0 & \\
\hline
\end{tabular}

Salmonella sp., and $1 \mathrm{~V}$. parahaemolyticus were detected by PCR assay not culturing, whereas additional 7 Salmonella sp. strains were isolated by culture other than PCR assay.

\section{DISCUSSION}

As the youngest city and one of the most vibrant cities in China, Shenzhen owned a special demographic feature. Young adults and transient population constituted a large percentage of the whole residents. As a result, the majority of the patients belonged to age group of $20 \sim 49$ years old $(203 / 412,49.3 \%)$ and $55.3 \%$ of the patients lived in the city transiently. There was no difference for the frequency of infection observed between the age group 20 49 years old (41.6\%) and others (41.4\%). However, the percentage of infection was significantly higher among transient population (104/228, 45.6\%) compared with the residents $(67 / 184,36.4 \%)$, which could be attributed to the residents' better hygiene condition. The weather would be another factor for affecting the pathogen spectrum of the acute diarrhea. The summer season in Shenzhen could last from April through October and 372 of 412 samples were collected during this period. The prevalence of infection during April and October (159/372, 42.7\%) was higher than that during other months $(12 / 40,30.0 \%)$. This might due to the hot weather and rainy months which were associated with some bacterial infections (Adkins et al., 1987; Carlton et al., 2013).

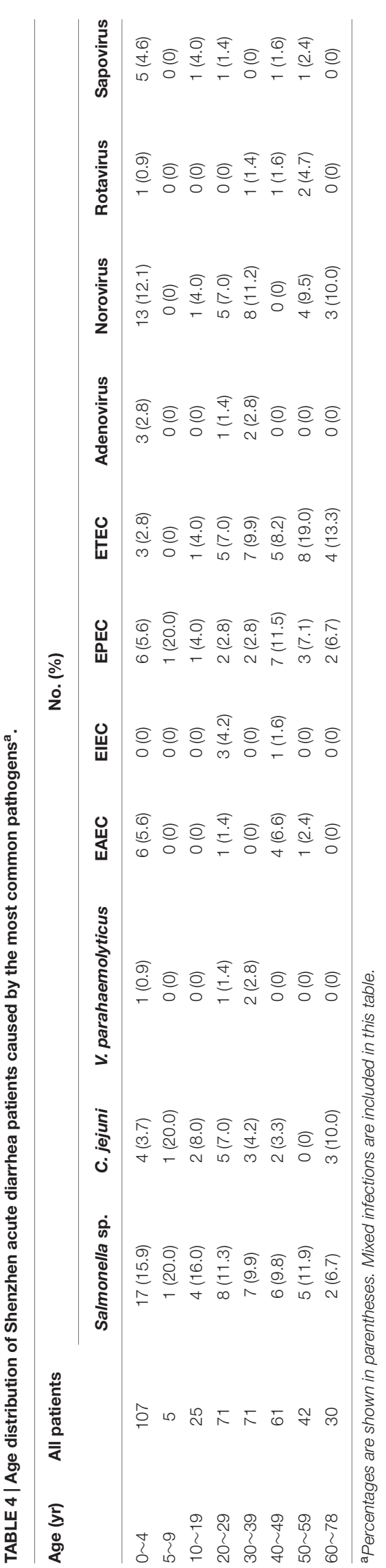


TABLE 5 | Distribution relative to patient age and gender of 40 Salmonella enterica isolates from acute diarrhea infections in Shenzhen, August 2014 through September, 2015.

\begin{tabular}{|c|c|c|c|c|c|c|c|c|c|}
\hline \multirow[t]{2}{*}{ Age (year) } & \multirow[t]{2}{*}{ No. of isolates } & \multicolumn{2}{|c|}{ No. of } & \multicolumn{6}{|c|}{ No. of isolates of } \\
\hline & & Males & Females & $\begin{array}{l}\text { Serovar } \\
\text { Enteritidis }\end{array}$ & $\begin{array}{c}\text { Serovar } \\
\text { Typhimurium }\end{array}$ & $\begin{array}{c}\text { Serovar } \\
\text { Senftenberg }\end{array}$ & $\begin{array}{l}\text { Serovar } \\
\text { Litchfield }\end{array}$ & $\begin{array}{l}\text { Serovar } \\
\text { Stanley }\end{array}$ & $\begin{array}{c}\text { Remaining } \\
\text { serotypes }\end{array}$ \\
\hline $0 \sim 4$ & 13 & 8 & 5 & 3 & 3 & 0 & 1 & 1 & 5 \\
\hline $5 \sim 9$ & 1 & 1 & 0 & 1 & 0 & 0 & 0 & 0 & 0 \\
\hline $10 \sim 19$ & 3 & 2 & 1 & 2 & 0 & 0 & 0 & 1 & 0 \\
\hline $20 \sim 29$ & 6 & 3 & 3 & 2 & 0 & 2 & 0 & 1 & 1 \\
\hline $30 \sim 39$ & 7 & 0 & 7 & 3 & 0 & 1 & 2 & 0 & 1 \\
\hline $40 \sim 49$ & 5 & 0 & 5 & 0 & 1 & 1 & 1 & 1 & 1 \\
\hline $50 \sim 59$ & 5 & 1 & 4 & 1 & 0 & 1 & 0 & 0 & 3 \\
\hline $60 \sim 78$ & 0 & 0 & 0 & 0 & 0 & 0 & 0 & 0 & 0 \\
\hline Total & 40 & 15 & 25 & 12 & 4 & 5 & 4 & 4 & 11 \\
\hline
\end{tabular}

A potential pathogen was detected for $41.5 \%$ of patients with acute diarrhea in the present study and coinfection was found for $7.0 \%$ of cases. The bacterial infection was the dominant cause of acute diarrhea in the southern coastal region of China, surpassing viral and parasite infection. DEC, Salmonella sp., and C. jejuni were the most frequently identified pathogens, followed by noro, sapo-, adenovirus, rotavirus, and V. parahaemolyticus. C. jejuni has generally not been tested for in microbiology laboratories in China, and the incidence of $C$. jejuni is therefore been seriously underestimated.

A number of case-control studies and cohorts on diarrhea have been conducted in the Netherlands (De Wit et al., 2001; Koopmans et al., 2001), the United Kingdom (Tam et al., 2012), and Australia (Barnes et al., 1998), and in these studies viruses were found to be the leading cause of diarrhea in community cases. Norovirus was observed as the most frequent pathogen in all age groups in the Dutch study (De Wit et al., 2001). Norovirus was the most commonly identified viral pathogen with a prevalence of $8.3 \%$ in this study. The associated infection could be found in all age groups except for age group $5 \sim 9$ years and $40 \sim 49$ years. This may due to the small sample size, as no association was found between the patient age and norovirus prevalence (Ahmed et al., 2014). The percentage attributable to noro-, sapo-, and rotavirus was clearly higher than our study (Koopmans et al., 2001). The viruses caused milder symptoms than bacterial pathogens, and thus patients with viral infections would be less likely to seek medical attention (Saphra and Winter, 1957; Lopman et al., 2004; Chen et al., 2007). Community studies are therefore expected to disclose a higher proportion of viral infections than studies involving patients admitted to hospitals. The fact that our specimens were collected clustering in April through November (August, 2014 to November, 2014 and April, 2015 to September, 2015) may also diminished the frequency of viruses' detection, because the seasonal prevalence for viruses was seen in the period from January to May (Olesen et al., 2005).

Diarrheagenic Escherichiacoli was found in 16.5\% of patients with diarrhea and identified as the most common enteric pathogen in the present study. Of the 68 DEC infections, 45 were identified as positive by both isolation and direct PCR assay, and
3 and 20 were identified as positive by only isolation or direct PCR assay, respectively. The direct PCR method was much more sensitive than the conventional culture, which may due to the errors of selecting putative colonies. A total of $29.4 \%$ of cases with DEC infection were co-infected with other organisms, showing the weak correlation between DEC infections with diarrhea. Some notable features occurred in DEC infections, including that most EAEC infections (7/11) were found in May and June, and ETEC infections (33/34) were mainly found in hot wet months of May through September and one ETEC strain isolated from a male patient aged 44 years harbored both sth and $l t$ virulence gene, both sth and $l t$ positive was not found frequently. These features needed a larger sample size to be confirmed and may be predictive for clinical diagnostics.

Of the 13 serotypes of Salmonella sp. identified in this study, the serovar Enteritidis was dominant throughout the surveillance period, followed by $S$. Senftenberg, S. Typhimurium, S. Litchfield, and S. Stanley. In addition to these Salmonella serotypes, some less common serotypes were identified, which included $S$. Uganda, S. Chomodey, S. Fillmore, and $S$. papuana. A total of two isolates were untypable. With regard to $S$. Enteritidis, our finding was in agreement with previous study conducted in Guangdong Province that $S$. Enteritidis mainly caused human salmonellosis in adults (Ke et al., 2014). However, the number of patients caused by $S$. Senftenberg ranked the second, which differed from previous study conducted in this area but was consistent with the surveillance data in Shanghai, China (Xu et al., 2009). The Shanghai study showed that $S$. Senftenberg was the second most common identified Salmonella serotype in individuals in foods and service industries (Zhu et al., 2008), and thus the customers were more likely infected with $S$. Senftenberg through contaminated foods, if hygiene and cooking practices were not adequate. More interestingly, among five strains of $S$. Senftenberg recovered from diarrheal patients, two atypical strains' hydrogen sulfide was negative. The phenotype and genetic character of these atypical Salmonella strains is under way.

Campylobacter jejuni infections has been the leading cause of bacterial gastroenteritis reported in the developed countries 
(Tauxe et al., 1992; Altekruse et al., 1999). However, few surveillance of C. jejuni was conducted and the associated disease burden was seriously underestimated in China. In the present study, $4.9 \%$ (20/412) of samples was found to be positive for C. jejuni, indicating that $C$. jejuni has been an important pathogen in Shenzhen. The detection rate was significantly higher than that reported in other cities of China including Yangzhou, Beijing, and Wuxi (Zhou et al., 2008; Huang et al., 2009; Liu et al., 2014), which may due to the common consumption of chicken and meat in southern China. C. jejuni was found in many foods of animal origin. Surveys of raw agricultural products support epidemiologic evidence implicating poultry, meat, and raw milk as sources of human infection (Altekruse et al., 1999). Most retail chicken and meat products were contaminated with C. jejuni (Boer and Hahné, 1990; Yang et al., 2003; ZhiFa et al., 2009), and thus the customers could easily get infections through eating undercooked or cross-contaminated foods. There were only two cases of coinfection found in C. jejuni infection, indicating the strong association with disease. In addition, An average number of five stools per day was found in C. jejuni infected patients, suggesting C. jejuni infection could cause severe diarrhea. The Yangzhou survey showed that children under 7 years of age had higher prevalence rate than that of other age groups $(\mathrm{Xu}$ et al., 2008), whereas the detection frequency was much higher in both age group 5 9 years (20.0\%) and 60 78 years $(10.0 \%)$ than that of children under 5 years old $(3.7 \%)$ in this study. The discordance between the two surveys might be the result of regional differences and small sample size of the present study.

Only four cases of $V$. parahaemolyticus were detected, which differed from previous survey that $V$. parahaemolyticus has been the leading cause of bacterial infectious diarrhea in coastal regions of China (Li et al., 2014). The low frequency of isolation of $V$. parahaemolyticus may due to the improvement in hygiene and thus the consumption of undercooked or cross-contaminated shellfish decreased, which was commonly associated with $V$. parahaemolyticus infection. All the three isolates serotyped as $\mathrm{O} 3: \mathrm{K} 6$ were $t d h+t r h-$, which was consistent with the surveillance data collected in Shenzhen that O3:K6 serotype was dominant in this region (Li et al., 2014).

The intestinal parasites infection was associated with the source of water supply, age and socioeconomic status (Leach et al., 2000). In the counties with poor sanitation, the prevalence of the three organisms could be very high (Kelsall and Ravdin, 1994; Leach et al., 2000). In addition, parasites-caused diarrhea could be commonly found in the immune-compromised individuals (Esfandiari et al., 1997). The improvement of sanitation in the big city, the consumption of boiled water, and no $\mathrm{HIV}$-infected cases in these enrolled patients might contribute to the non-infection of intestinal parasites. Furthermore, the ability of PCR method in distinguishing E. histolytica and E. dispar could result in a lower but true prevalence of E. histolytica (Verweij et al., 2004), as more than $90 \%$ of E. histolytica infections are responsible for E. dispar (Clark, 1998). Similarly, the non-infection of EHEC may benefit from the habit of consumption of cooked food and improvement of hygiene, as most of the EHEC-associated outbreaks was transmitted through contaminated foods (Viazis and Diez-Gonzalez, 2011). It was consistent with our previous surveillance data that EHEC had a very low prevalence $(4 / 11860,0.03 \%)$ in this region (Chen et al., 2014).

This study had several limitations. Firstly, all the samples were collected in a hospital and the results may not be representative of distinct districts of this region. The hospital that diarrheal patients visited may be associated with their income, living address, and severity of illness which subsequently influence the prevalence of enteropathogens. Secondly, the limited sample size may influence the analysis of the seasonal patterns and population distribution of major enteropathogens. Therefore, the positive percentage of enteropathogens among some age groups may be overly represented due to the small sample size. Thirdly, only one-year-period data were collected, so long-term trends were not present in this study. Nevertheless, this was the most comprehensive data collection on the etiology of diarrhea in this region. The full range detection of entropathogens and the fact that the municipal sentinel hospital received patients from each district of Shenzhen made these results reasonably representative. It is anticipated that further long-term continuation and collection of surveillance data from more sentinel hospitals will be able to overcome these limitations.

\section{CONCLUSION}

Bacterial pathogens were confirmed as the leading cause of acute infectious diarrhea in outpatients in Shenzhen. DEC was the most common enteric pathogen and ETEC was mainly detected in hot wet months of May through September. The distribution of 13 serotypes identified revealed the diversity of Salmonella sp., which might explain the continuing epidemic of Salmonella sp. Infections in this region. The high frequency of single infection of $C$. jejuni and its associated severe manifestations indicate the strong association with diarrhea, and the disease burden attributed to $C$. jejuni has been seriously underestimated. The phenotype and genetic character of atypical Salmonella strains and a large surveillance survey on C. jejuni is under way. A longterm surveillance at more sentinel hospitals could provide a better understanding of diarrheal illnesses.

\section{AUTHOR CONTRIBUTIONS}

HS, JZ, and YL were involved in the collection of samples and detection of enteropathogens. SX and YJ collected the clinical data. YW, YY, and HY offered great help in the sample collection. $\mathrm{HM}$ and CS offered great help in the data analysis. QH designed this study. HS and QH drafted and revised this manuscript.

\section{ACKNOWLEDGMENTS}

This work was supported by China National Science and Technology Major Project (No. 2016ZX10004215-005-005), 
Shenzhen Science and Technology Project (No. CXZZ2014041 1105636301), Shenzhen Science and Technology Innovation Committee (JCYJ 20140415162543001), and Futian District

\section{REFERENCES}

Adkins, H., Escamilla, J., Santiago, L., Ranoa, C., Echeverria, P., and Cross, J. (1987). Two-year survey of etiologic agents of diarrheal disease at San Lazaro Hospital, Manila, Republic of the Philippines. J. Clin. Microbiol. 25, 1143-1147.

Ahmed, S. M., Hall, A. J., Robinson, A. E., Verhoef, L., Premkumar, P., Parashar, U. D., et al. (2014). Global prevalence of norovirus in cases of gastroenteritis: a systematic review and meta-analysis. Lancet Infect. Dis. 14, 725-730. doi: 10.1016/S1473-3099(14)70767-4

Allos, B. M. (2001). Campylobacter jejuni infections: update on emerging issues and trends. Clin. Infect. Dis. 32, 1201-1206.

Altekruse, S. F., Stern, N. J., Fields, P. I., and Swerdlow, D. L. (1999). Campylobacter jejuni-an emerging foodborne pathogen. Emerg. Infect. Dis. 5, 28. doi: 10.3201/ eid0501.990104

Bai, Y., Dai, Y.-C., Li, J.-D., Nie, J., Chen, Q., Wang, H., et al. (2004). Acute diarrhea during army field exercise in southern China. World J. Gastroentero. $10,127-131$

Barnes, G. L., Uren, E., Stevens, K. B., and Bishop, R. F. (1998). Etiology of acute gastroenteritis in hospitalized children in Melbourne, Australia, from April 1980 to March 1993. J. Clin. Microbiol. 36, 133-138.

Blackstone, G. M., Nordstrom, J. L., Vickery, M. C., Bowen, M. D., Meyer, R. F., and DePaola, A. (2003). Detection of pathogenic Vibrio parahaemolyticus in oyster enrichments by real time PCR. J. Microbiol. Meth. 53, 149-155. doi: 10.1016/S0167-7012(03)00020-4

Boer, E. D., and Hahné, M. (1990). Cross-contamination with Campylobacter jejuni and Salmonella spp. from raw chicken products during food preparation. J. Food Protect ${ }^{\circledR}$. 53, 1067-1068.

Carlton, E. J., Eisenberg, J. N., Goldstick, J., Cevallos, W., Trostle, J., and Levy, K. (2013). Heavy rainfall events and diarrhea incidence: the role of social and environmental factors. Am. J. Epidemiol. 179, 344-352. doi: 10.1093/aje/kwt279

Chen, Q., Shi, X., Li, Y., Jiang, Y., Lin, Y., Qiu, Y., et al. (2014). Rapid genetic typing of diarrheagenic Escherichia coli using a two-tube modified molecular beacon based multiplex real-time PCR assay and its clinical application. Ann. Clin. Microbl. Anti. 13:30. doi: 10.1186/s12941-014-0030-8

Chen, S.-Y., Chang, Y.-C., Lee, Y.-S., Chao, H.-C., Tsao, K.-C., Lin, T.-Y., et al. (2007). Molecular epidemiology and clinical manifestations of viral gastroenteritis in hospitalized pediatric patients in Northern Taiwan. J. Clin. Microbiol. 45, 2054-2057. doi: 10.1128/JCM.01519-06

Clark, C. G. (1998). Amoebic disease: Entamoeba dispar, an organism reborn. Trans R. Soc. Trop. Med. Hyg. 92, 361-364. doi: 10.1016/S0035-9203(98)91049-5

Clarke, S. C., Haigh, R. D., Freestone, P. P., and Williams, P. H. (2003). Virulence of enteropathogenic Escherichia coli, a global pathogen. Clin. Microbiol. Rev. 16, 365-378. doi: 10.1128/CMR.16.3.365-378.2003

Davis, C. R., Heller, L. C., Kealy Peak, K., Wingfield, D. L., Goldstein-Hart, C. L., Bodager, D. W., et al. (2004). Real-time PCR detection of the thermostable direct hemolysin and thermolabile hemolysin genes in a Vibrio parahaemolyticus cultured from mussels and mussel homogenate associated with a foodborne outbreak. J. Food Protect ${ }^{\circledR}$. 67, 1005-1008.

De Wit, M., Koopmans, M., Kortbeek, L., Wannet, W., Vinje, J., Van Leusden, F., et al. (2001). Sensor, a population-based cohort study on gastroenteritis in the Netherlands: incidence and etiology. Am. J. Epidemiol. 154, 666-674. doi: 10.1093/aje/154.7.666

Denno, D. M., Shaikh, N., Stapp, J. R., Qin, X., Hutter, C. M., Hoffman, V., et al. (2012). Diarrhea etiology in a pediatric emergency department: a case control study. Clin. Infect. Dis 55, 897-904. doi: 10.1093/cid/cis553

Esfandiari, A., Swartz, J., and Teklehaimanot, S. (1997). Clustering of giardiosis among AIDS patients in Los Angeles County. Cell. Mol. Biol. (Noisy-le-Grand, France). 43, 1077-1083.

Fischer Walker, C. L., Sack, D., and Black, R. E. (2010). Etiology of diarrhea in older children, adolescents and adults: a systematic review. PLoS Negl. Trop. D 4:e768. doi: 10.1371/journal.pntd.0000768

Hu, Q., Lyu, D., Shi, X., Jiang, Y., Lin, Y., Li, Y., et al. (2014). A modified molecular beacons-based multiplex real-time PCR assay for simultaneous detection of
Public Health Research Project (FTWS2015043). We thank the staff of the laboratories who took part in the study.

eight foodborne pathogens in a single reaction and its application. Foodborne Pathog Dis. 11, 207-214. doi: 10.1089/fpd.2013.1607

Huang, J., Xu, H., Bao, G., Zhou, X., Ji, D., Zhang, G., et al. (2009). Epidemiological surveillance of Campylobacter jejuni in chicken, dairy cattle and diarrhoea patients. Epidemiol. Infect. 137, 1111-1120. doi: 10.1017/S0950268809002039

Huilan, S., Zhen, L. G., Mathan, M., Mathew, M., Olarte, J., Espejo, R., et al. (1991). Etiology of acute diarrhoea among children in developing countries: a multicentre study in five countries. Bull. World Health Organ. 69, 549-555.

Jiang, Y., Fang, L., Shi, X., Zhang, H., Li, Y., Lin, Y., et al. (2014). Simultaneous detection of five enteric viruses associated with gastroenteritis by use of a PCR assay: a single real-time multiplex reaction and its clinical application. J. Clin. Microbiol. 52, 1266-1268. doi: 10.1128/JCM.00245-14

Ke, B., Sun, J., He, D., Li, X., Liang, Z., and Ke, C.-W. (2014). Serovar distribution, antimicrobial resistance profiles, and PFGE typing of Salmonella enterica strains isolated from 2007-2012 in Guangdong, China. BMC Infect. Dis. 14:338. doi: 10.1186/1471-2334-14-338

Kelsall, B., and Ravdin, J. (1994). Amebiasis: human infection with Entamoeba histolytica. Prog. Clin. Parasitol. 4, 27-54.

Koopmans, M. P., Kortbeek, L. M., van Leeuwen, N. J., Vinjé, J., and van Duynhoven, Y. T. (2001). Etiology of gastroenteritis in sentinel general practices in the Netherlands. Clin. Infect. Dis. 33, 280-288. doi: 10.1086/321875

Kosek, M., Bern, C., and Guerrant, R. L. (2003). The global burden of diarrhoeal disease, as estimated from studies published between 1992 and 2000. Bull. World Health Organ. 81, 197-204.

Leach, C. T., Koo, F. C., Kuhls, T. L., Hilsenbeck, S. G., and Jenson, H. B. (2000). Prevalence of Cryptosporidium parvum infection in children along the Texas-Mexico border and associated risk factors. Am. J. Trop. Med. Hyg. 62, 656-661.

Li, Y., Xie, X., Shi, X., and Lin, Y. (2014). Vibrio parahaemolyticus, Southern Coastal Region of China, 2007-2012. Emerg. Infect. Dis. 20, 685-688. doi: 10. 3201/eid2004.130744

Liu, X.-Y., Yu, J.-F., Gu, Y.-X., Liang, H., and Zhang, M.-J. (2014). Laboratory detection and surveillance of Campylobacter jejuni infection. Dis. Surv. 29, 354-358.

Lopman, B. A., Reacher, M. H., Vipond, I. B., Sarangi, J., and Brown, D. W. (2004). Clinical manifestation of norovirus gastroenteritis in health care settings. Clin. Infect. Dis. 39, 318-324. doi: 10.1086/421948

Olesen, B., Neimann, J., Böttiger, B., Ethelberg, S., Schiellerup, P., Jensen, C., et al. (2005). Etiology of diarrhea in young children in Denmark: a case-control study. J. Clin. Microbiol. 43, 3636-3641. doi: 10.1128/JCM.43.8.3636-3641.2005

Parashar, U. D., Hummelman, E. G., Bresee, J. S., Miller, M. A., and Glass, R. I. (2003). Global illness and deaths caused by rotavirus disease in children. Emerg. Infect. Dis. 9, 565-572. doi: 10.3201/eid0905.020562

Qu, M., Deng, Y., Zhang, X., Liu, G., Huang, Y., Lin, C., et al. (2012). Etiology of acute diarrhea due to enteropathogenic bacteria in Beijing, China. J. Infect. 65, 214-222. doi: 10.1016/j.jinf.2012.04.010

Saphra, I., and Winter, J. W. (1957). Clinical manifestations of salmonellosis in man: an evaluation of 7779 human infections identified at the New York Salmonella center. New Engl. J. Med. 256, 1128-1134. doi: 10.1056/ NEJM195706132562402

Scallan, E., Hoekstra, R. M., Angulo, F. J., Tauxe, R. V., Widdowson, M.-A., Roy, S. L., et al. (2011). Foodborne illness acquired in the United States-major pathogens. Emerg. Infect. Dis. 17, 7-15. doi: 10.3201/eid1707.110572

Tam, C. C., O’Brien, S. J., Tompkins, D. S., Bolton, F. J., Berry, L., Dodds, J., et al. (2012). Changes in causes of acute gastroenteritis in the United Kingdom over 15 years: microbiologic findings from 2 prospective, population-based studies of infectious intestinal disease. Clin. Infect. Dis. 54, 1275-1286. doi: 10.1093/ $\mathrm{cid} / \mathrm{cis} 028$

Tauxe, R. V., Nachamkin, I., Blaser, M., and Tompkins, L. (1992). Epidemiology of Campylobacter jejuni Infections in the United States and other Industrialized Nations. Washington, DC: American Society for Microbiology.

Verweij, J. J., Blangé, R. A., Templeton, K., Schinkel, J., Brienen, E. A., van Rooyen, M. A., et al. (2004). Simultaneous detection of Entamoeba histolytica, Giardia 
lamblia, and Cryptosporidium parvum in fecal samples by using multiplex realtime PCR. J. Clin. Microbiol. 42, 1220-1223. doi: 10.1128/JCM.42.3.1220-1223. 2004

Viazis, S., and Diez-Gonzalez, F. (2011). Enterohemorrhagic Escherichia coli: the twentieth century's emerging foodborne pathogen: a review. Adv. Agron. 111, 1-50. doi: 10.1016/B978-0-12-387689-8.00006-0

Xu, H.-Y., Huang, J.-L., Bao, G.-Y., Gao, Y., Zhang, G., Su, J., et al. (2008). Prevalence and antimicrobial susceptibility of Campylobacter spp. in diarrhea patients in Yangzhou. Chin. J. Zoonoses. 24, 58.

Xu, X., Yuan, Z., Jin, H., Xiao, W., Gu, B., Chen, M., et al. (2009). Study on the epidemiological characteristics and molecular typing of Salmonella enterica subsp. enterica serovar Senftenberg in Shanghai. Chin. J. Epidemiol. 30, 933-937.

Yan, H., Yagyu, F., Okitsu, S., Nishio, O., and Ushijima, H. (2003). Detection of norovirus (GI, GII), Sapovirus and astrovirus in fecal samples using reverse transcription single-round multiplex PCR. J. Virol. Methods 114, 37-44. doi: 10.1016/j.jviromet.2003.08.009

Yang, C., Jiang, Y., Huang, K., Zhu, C., and Yin, Y. (2003). Application of realtime PCR for quantitative detection of Campylobacter jejuni in poultry, milk and environmental water. FEMS Immunol. Med. Microbiol. 38, 265-271. doi: 10.1016/S0928-8244(03)00168-8
ZhiFa, L., ChaoMan, S., and WeiYan, L. (2009). Survey of infectious status of poultry with Campylobacter jejuni in Shenzhen City. Chin. Trop. Med. 9:900.

Zhou, W.-J., Zhu, Y., and Ai, Y.-C. (2008). Surveillance for food-borne pathogens in Wuxi city during the period of 2005-2007. Mod. Prev. Med. 19:13

Zhu, J.-D., Zhang, X.-H., and Tian, Z.-G. (2008). Survey on the Salmonella-carrier state in individuals in foods and service industries of Shanghai port. J. Pathog. Biol. 1:28.

Conflict of Interest Statement: The authors declare that the research was conducted in the absence of any commercial or financial relationships that could be construed as a potential conflict of interest.

Copyright $\odot 2016$ Shen, Zhang, Li, Xie, Jiang, Wu, Ye, Yang, Mo, Situ and Hu. This is an open-access article distributed under the terms of the Creative Commons Attribution License (CC BY). The use, distribution or reproduction in other forums is permitted, provided the original author(s) or licensor are credited and that the original publication in this journal is cited, in accordance with accepted academic practice. No use, distribution or reproduction is permitted which does not comply with these terms. 